\author{
Ирина Коларска \\ irikol@abv.bg
}

\title{
Магията на словото и мълчанието в бреда - формули и функции
}

\begin{abstract}
Kolarska Irina, Magijata na slovoto i mylčanieto v obreda - formuli i funkcii (The Magic of Word and Silence in the Ritual - Formulas and Functions). „Poznańskie Studia Slawistyczne” 3. Poznań 2012. Adam Mickiewicz University Press, pp. 97-111. ISBN 978-83-232-2473-0. ISSN 2084-3011.

Beliefs and perceptions of word are based on existing mythological layer of culture that has specific mechanisms and functions. This mythological context of word determines its acceptance as a magical tool that has a certain force of impact. The power of speech is invisible, but exactly by the word, the individual and the community identify themselves and provide a link between past, present and future. One of the most significant events of word (or speech) is connected with its use in ritual. The reason of this is that the importance is attached to the ritual and to the consequences of its performing. Ritual word has an impact on society, and nature and the individual by verbal formulas that contribute to its realization. Depending on the ritual, word can both perform different functions and act as a specific magical tool.
\end{abstract}

Keywords: ritual word, magic, verbal formulas, functions, monological and dialogical forms of ritual words, silence

\section{1. Вярвания, представи и класификации на словото}

Магията на словото представлява имагинерна проекция на човешките мисли и желания. Значението и функциите му се определят от различни обстоятелства, с които то е поставено във взаимовръзка. Словото може да се възприема като компонент на културата, като „оръдие” на културата. Същевременно то е автономно по отношение на културата и като цяло може да се разглежда отделно от нея или да бъде сравнявано с нея като равнозначен, равноправен феномен ${ }^{1}$.

${ }^{1}$ Н.И. Толстой, Язык и народная культура. Очерки по славянской мифологии и этнолингвистике, Москва 1995, с. 16. 
Отделните култури имат специфично отношение към словото, изразено най-общо в две позиции:

1. Представата на древните гърци за устното слово като идентификационен белег, при който тялото и свързаните с него глас и реч биват одухотворявани, и представата за писаното слово, което се приема за безтелесно и чуждо на човешкия образ ${ }^{2}$.

2. Представата на древните юдеи, че именно писанието е сакрално и притежава тайнствена сила ${ }^{3}$.

Развитието на отношението към словото в различните култури върви от магично към логично и семантично разбиране, от слово-въплъщение към слово-значение ${ }^{4}$. И в двата случая силата, която се приписва на словото остава ненакърнима, макар да се проявява по различен начин.

Вярванията и представите за словото се базират на съществуващия митологичен пласт на културата, който притежава механизми и функционира по специфичен начин. Този митологичен контекст на словото обуславя възприемането му като магическо средство, което притежава определена сила на въздействие. Могъществото на словото е средство, чрез което индивидът и общността се определят и осьществяват връзката между минало, настояще и бъдеще.

Една от най-значещите прояви на словото е свързана с неговата употреба в обреда. Това се дължи на значението, което се придава на самия обред и последиците от неговото извършване. Във фолклорния обред е вплетена универсалната представа за цикличност на социалния живот и постигането на „раждането на новото” чрез смъртта на старото 5 . Обредът като време, пространство и действащи лица, е сакрална ситуация, в която словото се експонира. Митичното прониква във вижданията на човека за всичко ${ }^{6}$, а това обяснява и вярата в способността на обреда и неговите компоненти да оказват влияние върху социалната и природната среда. Като остатьк от тези вярвания

\footnotetext{
${ }^{2}$ Т. Живков, Слово, мит и магия, в: idem, Увод в Етнологията, Пловдив 2000, c. 162 .

${ }^{3}$ Ibidem.

${ }^{4}$ Е. Касирер, Изследване на човека, прев. Г. Апостолов, София 1996.

${ }^{5}$ М. Елиаде, Митът за вечното завръщане, прев. Л. Денкова, Г. Вълчинова, София 1994

${ }^{6}$ Т. Живков, оp. cit., с. 155.
} 
можем да разглеждаме благословиите, израз на обредното слово, чиято основна цел е чрез назоваването на изобилието, богатството, плодородието да се постигне тяхното проектиране в действителността. Или, както казва Потебня: най-често словото се използва като символично-симпатическа магия, чиято функция е да доведе до плодородие и здраве, а употребата му в обредно време има способността да произвежда онова, което означава ${ }^{7}$. Това се явява важна предпоставка за изследването на обредното слово в неговия социално значим аспект и ,магическата” натовареност на неговата функционалност.

Във фолклорния обред словото се осъществява се с помощта на различни формални и съдържателни средства. То е затворено в определена от „законите” на обреда рамка и вариативността и интерпретацията му са максимално редуцирани. За сметка на това са създадени множество видове слово, които имат свое място и функции в съответния ритуал. Обредното слово играе важна роля в процесите на преход. Изричането, говоренето в обредната ситуация допълва обредното действие на ниво слово за постигане на желаната ефективност на обредния комплекс. Проявленията на словото във фолклорния обред могат да се разглеждат по различни признаци: структура (на словото), начин на изпълнение, обредни лица, „жанрова принадлежност",

При изследването на обредното слово в друг, по-голям труд 9 приех следната класифицикация на обредното слово:

1. Монологични форми на обредно слово.

- Кратки монологични форми.

- Дълги монологични форми.

2. Обредно мълчание.

3. Диалогични форми на обредно слово.

Кратки монологични форми в обреда са благопожеланията, съставени от едно (просто или сложно) изречение, гаданията за женитба (ладванки), клетвите и др. Употребени в обреда, те добиват нова сим-

\footnotetext{
${ }^{7}$ А. Потебня, Из записок по теории словесности, Харьков 1905, с. 162.

${ }^{8}$ Понятието жанр е относително за фолклорния обред, защото не съществува единен критерий за определянето на фолклорните жанрове.

${ }^{9}$ И. Коларска, Функции на словото във фолклорния обред (Календарна и семейна обредност), дисертационен труд за добиване на научнообразователна степен доктор, 2005.
} 
волика и семантична натовареност. В обредното време те са очаквани и желани ${ }^{10}$ и представляват психологически фактор с пророческа и гадателска функция.

Към дългите монологичи форми на обредно слово спадат наричанията под формата на благословии (благопожелания), гадания, клетви, сквернословията и оплакванията, съставени от няколко части, свързани със съюз. Например, благословиите на станеника при коледарите, на водача при сурвакарите, царя или бея при кукерите и др. са ритмични текстове, които носят цялостната идеята на обреда. При монологичното обредно слово не се очаква отговор във вербален план, докато при диалозите такъв е необходим като част от структурата на текста. Диалогичната проява на словото се среща при всички видове обреди, но има своя специфика и се придържа към определени формули. Обредните диалози могат да бъдат разделени на подгрупи, в зависимост от сакралните действия, които ги съпровождат ${ }^{11}$, а също така и по функции. Протичащата на словесно равнище комуникация между обредните лица отговаря на реалното обредно действие само по символен път. Към тази група спадат също и гатанките, които се задават като съставна част от конкретен обред - свързани обикновено с изпитване на обредни лица, намиращи се в позиция на преход.

\section{2. Вербални формули и видове обредно слово}

Словото в обреда функционира посредством вербални формули, които спомагат за формализирането, заучаването и придаването на неизменност. Под формула ще разбираме общата схема, по която се изгражда структурата на обредното слово. В буквален смисъл думата формула означава фиксиран, установен, повтарящ се общовалиден израз. Към това значение можем да добавим и идеята за съкращение, сгъстяване, дори шифър, който обобщава дадена информация ${ }^{12}$.

${ }^{10}$ М. Арнаудов, Благопожелания и клетви, в: idem, Очерци по Български фолклор, т. I-II, София 1996, с. 655.

${ }^{11}$ Н.И. Толстой, ор. cit., с. 13.

${ }^{12}$ H. Bausinger, Formen der „,Volkspoesie”. Grundlagen der Germanistik 2, Berlin 1980, c. 70 . 
В езикознанието е важно доколко езикът може да се сведе до прецизни информационни опорни точки, установява се шифровият характер на езика или с други думи, неговата формулна структура. Именно тези специфики на употребяваните в обреда изрази са водещи при извеждането на формулите, чрез които обредното слово функционира. С тяхна помощ словесният текст се усвоява по-лесно и се поддава на интерпретация и създаване на нови варианти; превръща се в средство, чието приложение гарантира успеха на търсения резултат. В зависимост от контекста на употребата им, вербалните формули могат да имат сходно или противоположно значение и функция. В езиково отношение те са предварително формулирани и нормирани и определят не само първоначалното установяване на контакт, а и по-нататъшни стъпки в диалога ${ }^{13}$.

Формулата е обективен факт, повтаряемо колективно благо; тя покрива определена смислова област, но може да бъде натоварена субективно с много различни значения. Чрез нея могат да бъдат изразени всички нюанси на емоционален ангажимент - от възторга до критичната ирония, без тя да променя външния си облик.

Х. Баузингер изследва езиковите формули и стига до извода, че те могат да бъдат носители на различни функции. Той ги разделя в няколко основни групи: за установяване на контакт, за пожелание или настоятелно искане (например благословиите и исканията на коледарските и други групи), за контакт с висшите сили (култови заклинания и молитви).

От друга страна, още Я. Грим в книгата си Немска митология говори за съществуването на „магическа формула”, прилагана в заклинанията и благословиите. Той отбелязва, че в думата има по-голяма сила отколкото в билката и в камъка и че благословиите и проклятията представляват обвързана реч, за която са необходими „съзнателно подбрани думи” - verba concepta. Изреченото в обреда се разграничава от ежедневната реч, обособява се в него като област, в която словото има особена мощ ${ }^{14}$. Обредното слово дава възмож-

\footnotetext{
${ }^{13}$ Ibidem.

${ }^{14}$ Ibidem, c. 80.
} 
ност за осъществяването на общуването както между обредните лица, така и между света на живите и света на мъртвите и по своята същност то представлява основно средство за комуникация ${ }^{15}$.

\section{1. Монологични форми на обредно слово - формули и функции}

Анализът на обредното слово показва, че всички негови форми са съставени от определени формули, които формализират и улесняват създаването, заучаването и употребата му. Така например кратките монологични форми са съставени от прости изречения в повелително наклонение (,Да пораснеш голямо!, Да имаш много пилци!, Да даде Господ берекет!" и т.н.).

Дьлгите форми на обредно слово са съставени от сложни съчинени или съставни изречения. Структурата на съчинените изречения е изградена от последователното свързване на прости изречения, посредством съчинителните съюзи. С помощта на повелителното наклонение проявата на речта в обреда се преврьща във вербална формула, която има магическата способност да въздейства върху културната и природната среда и изпълнява продуцираща функция. Съставните изречения са изградени с помощта на съюзите колкото - толкоз, като, както - така и др. С тяхна помощ се изграждат устойчиви формули, в които се вграждат подходящи пожелания и сравнения. Този тип конструкции дават възможност да се изведат няколко формули:

a) При благопожелания от типа „Да са живи и здрави като желязото" целта е да се постигне желания резултат чрез уподобяване на качества, посредством помощта на съюза като. Този тип конструкции имат две части, първата (А) се състои от пожелание за придобиването на дадено качество (едно или повече), а във втората (Б) е въведен предмет с константно качество, равно на онова, което е зададено в началото (А) на благословията. Така се откроява формулата „А като Б”.

15 Други средства за комуникация, използвани в обреда са жестовете, действията, танците и др. 
б) В случаите, когато се използва съюз колкото - толкова, формулата е „колкото А, толкова Б”, където А е константното изобилие (,колкото звезди в небето”), а Б е обектът на обредното благопожелание (,,толкова кръстци в полето”) ${ }^{16}$. Или условието на формулата изисква реализиране на съответното количество от „пожеланото”, за постигането на равенство в уравнението, т.е. плодородие, здраве, имот, стока. Така проектираното количество символизира желаното благополучие.

в) Друг вид вербална формула е тази, с която се определя начинът, по който се добива благополучието - лесно, бързо и т.н. Структурата на този тип благопожелания залага на сложни съставни изречения, които се изграждат с помощта на съюзни връзки, обвързващи двете части на изречението и поставящи ги във взаимна зависимост: „както А, така Б” („Къкто тече тая кръв в тая вода, така да вървят, да съ въдят ягнета!", АИФ II 30 I, с. 30). С подобни синтактични конструкции словото задвижва механизмите за въздействие върху плодородието в земеделски, стопански и социален план и функционира като продуцираща магия. Този тип словесни формули е широко прилаган в различни обреди както от семейния, така и от календарния цикъл. Ако първата група има вид на заклинание, което трябва пряко да въздейства, то втората група оказва въздействие с помощта на сравнение. Уподобяването на количество или благосъстояние има за цел да доведе до „случване” на пожеланото. Изказната форма е отново в повелително наклонение, а употребата му може да се разглежда като внушение на езиково равнище за неизбежността на търсения резултат.

Съчетаването на няколко благопожелания в едно единно организирано слово води до изграждането на дългите монологични форми. Колкото по-сложна е структурата и повече сравнения се използват, толкова по-сполучливо е вербалното въздействие върху труда и бита на човека. Към дългите форми могат да бъдат отнесени благословиите на полазника, коледаря, кукерския цар (при заораването) и др.

Монологични форми на обредно слово в родилната обредност имат за цел да предпазят бъдещата майка и бебето от тежко раждане,

\footnotetext{
${ }^{16}$ Колко здравец по планина, толкоз здраве в тази кьща! И т.н.
} 
от влияние на зли сили, а понякога дори от смърт. Обредното слово и действия са насочени към осигуряването на благополучен изход и защита. Общността се стреми да осигури успешното преминаване на индивида през преходния период и последващата му социализация. Съдържателната страна на благословиите е насочена към „предначертаването" на бъдещето на новороденото чак до сватбата. Градацията е от особено значение, тъй като задава общоприетите социални норми. Така магията на словото влияе върху бъдещето на новороденото и социума и изпълнява социализиращата и превантивната.

Монологични форми на обредно слово се срещат в различни фази на сватбата. Тъй като тя е събитие, което предизвиква множество промени, както в живота на отделния индивид, така и в живота на социума словото играе роля на регулатор на обществото. То има за цел да предпазва и да осигурява благополучно развитие на обреда. Изричат се различни благопожелания и благословии, които имат за цел да предвещаят и осигурят сполучлив годеж и успешен брак за новото семейство. Съдържанието на кумовата благословия, напр. често очертава бъдещия живот на семейството, добиването на деца и внуци, стока ${ }^{17}$, с което изпълнява едновременно продуцираща и регулативна функция.

Както при всички останали случаи, и при смърт се налага да се премине през поредица от обреди и обредни практики за отделянето на мъртвия от социума на живите и подготвянето му за света на мъртвите. Такива са погребението и помените. Използват се формули за изказване на съболезнования, които обвързват индивидуалните емоции с общата традиция. Използваните в тези случаи изрази-формули са свързани с раздялата с мъртвия и молба към Бога за опрощаване на душата и осигуряване на безпрепятственото й преминаване в отвъдното. Насочени са конкретно към „новия статус” на покойника и спомагат за интегрирането му в света на предците-покровители. Целта на обредното слово при нарежданията, изричани при опалване на гроб е да се прекъсне обратния път към света на живите.

\footnotetext{
${ }^{17}$ Под стока се има предвид животни в стопанството.
} 


\section{2. Диалогични форми на обредно слово}

Като езикова проява, в която участват две или повече лица обредният диалог може да се разглежда като пряка реч, с която обредните лица по непосредствен пьт изразяват желанията на социума за бъдещо благополучие. Към него се прибягва за създаване на по-силно внушение. Поради това той се определя като средство за комуникация, за осъществяване на контакт и размяна на информация.

Обредните диалози могат да се класифицират въз основа на различни показатели - съобразно обредните лица и техните характеристики (пол, брой, възраст, отношение към дома и т.н.) или в зависимост от сакралните действия, които ги съпровождат. Те могат да бъдат разделени по функции и/или класифицирани в следните групи: при криене зад обредни предмети, при „засичане” на нераждащи дървета, при полазване, при внасянето на бъдника в дома, при гадаене за плодородие на Еньовден, при прогонване на вредители, при искане на прошка на Сирница (в календарната обредност) и при кръщене, при сватосване, при договаряне на даровете на годежа, при обещаване на дарове на сватба, при задаване на гатанки на сватбената трапеза, при отговяване (в семейната обредност).

В структурно отношение можем да изведем две основни формули: 1. въпрос и отговор и 2. редуване на повествователни и повелителни изречения. Диалозите могат да бъдат кратки, съставени от ограничен брой въпроси и отговори или да имат разширени варианти, в зависимост от уменията за импровизация на обредните лица и действията, които се извършват.

В диалога трябва да се постигне цялостна реализация на основната идея. За целта се прибягва до формулни изречения и фразеологизми, които, от една страна, ограничават възможността за импровизация, а от друга, дават възможност по асоциативен път да се осъществи задачата на ритуала. Често обредните диалози са така структурирани, че един и същи диалог може да се използва в различни календарни или семейни обреди. Такъв е примерьт с обредния диалог при криене зад предмети. Криенето се извършва зад натрупани купчини от продуктите на човешкия труд, което има за цел на ниво предмет-действие да символизира плодородие - хляб, снопи, грозде, 
вино, кожи. Количеството на предметите се явява важен фактор, който задава представата за множество, за изобилие.

В основата на диалога могат да стоят въпроси, отнасящи се до действието, което се извършва в момента на говорене (напр.: „Какво правиш,...?”, „Защо режеш тая слива?”) или свързани с търсенето и криенето на едно от обредните лица (напр.: „Виждам ли се?”, „Трифуне, къде си?").

Отговорът може да носи и пожелателна или заклинателна функция, чрез която се проектира по-голамо изобилие в бъдещето, напр.: „Са те видимо и не, а догодина ич да те не видимо!”18 или: „Виждаме тъ, виждаме тъ!" - което означавало, че имало още невести да идват, чийто хляб щял да скрие напълно бабата (АИФ 174: $6^{19}$ ).

Важно за продуциращата магия е противопоставянето в диалога на опозиционните двойки сега - догодина, виждаме и не - да не виждаме, което трябва да допринесе за увеличаването стопанската продукция през предстоящата година. Формулата, а и самият диалог са приложими, както в коледната обредност, така и на Бабинден, Трифоновден, Гергьовден, Димитровден и др. Обредните лица обикновено са с различна социална роля, което означава, че се осьществява комуникация от асиметричен тип ${ }^{20}$. От друга страна, едното от лицата е натоварено с медиативни способности, което очертава и вертикалния тип комуникация, който се осъществява чрез обредния диалог. Функциите, които обредното слово изпьлнява в тези ситуации са комуникативна и продуцираща.

С помощта на предварително установени формули се развиват и диалозите при заплашване на ялови дръвчета, животни (или булки). Те се изричат при обреди, свързани със смяна на годишните времена - Бъдни вечер, Коледа, Трифоновден, Великденска обредност ${ }^{21}$.

${ }^{18}$ Н.И. Толстой, Очерки славянского язычества, Москва 2003, с. 320.

${ }^{19}$ АИФ 174, 6, Варненско, зап. Л. Миков.

${ }^{20}$ В. Кузманова, Комуникативно поведение на изпълнителя и контекст на общуване, в: Проблеми на българския фолклор. Фолклор, език и народна съдба, т. IV, съст. П. Динеков, София 1979, с. 93.

${ }^{21}$ Напр. заплашване на дръвчета, които не раждат - на Свето Четиресе, Лазаровден, Цветница и Великден в Бургаско:

„Излезе един, земе брадвата, другия седи до него и той сече. Оня вика:

- Какво сечеш? 
Обредните лица обикновено са с неравностоен социален статус (от различен пол или възрастова група). Комуникацията, която се осъществява чрез този тип обредни диалози, предопределя тяхната продуцираща функция. Словото има за цел по магически начин да повлияе регулативно върху природата, животните или дома, като осигури нужното увеличаване на домакинството или рода.

Синтезирането на обреди с продуцираща, прогностична и превантивна функция е характерно за зимните календарни празници. Една от тези обредни практики е полазването, чието обредно време се свързва с Игнажден и Варвара. Изпълнението на обредния диалог се извършва чрез формулата въпрос-отговор (,какво носиш? - пиленца, агънца, парички, жълтички, здраве" [АЕИМ 515 II: $\left.9^{22}\right]$ ). Съдържанието на обредния диалог представлява символично внасяне на плодородие в дома и изпълнява продуцираща магия.

Интересна реализация на магическото въздействие на словото се наблюдава при извършването на обредното гадаене в еньовденската обредност. В него главното обредно лице е момиченце (Еня) на възраст от 3 до 5 години, което няма право да ходи, нито да пее или да играе, както правят момите (другите лица в обреда). Това ги поставя в опозиция на равнище действие-бездействие. Бездействието е типична характеристика за света на мъртвите, което потвърждава медиативната роля на Енята като посредник между света на живите и света на предците. В Югоизточна България обредната обиколка завършва край река, при което се реализира и гадаенето за плодородие чрез формулата въпрос-отговор. Задаваните въпроси („Сита ли си?”, „Ще има ли пченица?”, „Ще има ли царевица?”, „Ще има ли вино?”) могат да получат положителен или отрицателен отговор, които продричат бъдещата реколта ${ }^{23}$. Смята се, че ако отговорьт на Енята е отрица-

- Сека крушата - вика.

- Защо я сечеш?

- Щото не връзва.

Недей я сяка, тя тъз година ше връже сто и четирисе круши”, АИФ 353, Бургаско, зап. А. Анчев, с. 93.

${ }^{22}$ АЕИМ 515 II, 9, Шуменско, зап. И. Георгиева.

${ }^{23}$ Д. Маринов, Избрани произведения, т. I, София 1981, с. 662. 
телен, то за него може да се търси причината в нарушение на социалните и нравствени закони (мома ако зачене, ако някоя жена е съгрешила и пр.).

Сред важните свойства на обредното слово е осигуряването на защита и сигурност за стопанството и дома (превантивна функция). Диалозите, чиято основна роля е постигането на защита от хищници и гризачи се изричат в дните получили съответно названията „мишин ден”, ,мишов ден”, „вълчи празници” и пр. Чрез словото се изяснява смисъла на извършваната практика и същевременно се разчита на способността му да влияе върху природните сили. Таво дава основание сходни формули могат да се използват срещу различни вредители. Вербалната формула отново е въпрос-отговор, като въпросът изисква пояснение на извършваното действие (,какво правиш?”), а отговорът е натоварен със семантиката на обредната практика. В зависимост от извършваните обредни действия и тяхната последователност, се изменя и обредният диалог, който пояснява всяка една от дейностите. Съществуват варианти, в които символично се сышиват или връзват очите, а в Габровско добавят още ушите, устата на мишките (или вълците), както и пояснението защо се прави това: „да не виждат, да не чуват, да не хапят" (АЕИМ 515 II: 8). Извършваното върху даден предмет действие се пренася върху обекта на обредната практика с помощта на обредното слово. Така главният обреден персонаж извършва имитативна магия и обезврежда евентуалните вредители, а обредният диалог играе превантивна функция. Диалозите се изричат по три пъти за всяка от извършваните дейности. Така, освен че ритуалният диалог функционира по закона на уподобяванет $^{24}$, се увеличава заклинателната сила и въздействието на обредното слово.

В семейната обредност диалогичната проява на словото има предимно социализираща функция. Чрез нея се подготвят за настьпващите промени в социалната структура едновременно и лицата в състояние на преход, и обществото, което подлежи на трансформация.

${ }^{24}$ П.Г. Богатырев, Вопросы теории народного исскуства, Москва 1971, с. 32-33; В.К. Соколова, Весенне-летние календарные обряды русских украинщев и белорусов ХІХ - начало ХХ в., Москва 1979, с. 166. 
Такива обредни диалози срещаме при обреди като крьщене, сватосване, годеж, сватба и следсватбените обредни практики. Способността на словото да осъществява общуването между обредните лица и да влияе върху тяхната реализация в обществото. При сватбата например диалогът е важен елемент за усвояването на чуждия/чуждите и разпознаването иденму/им по-нататък като свои (социализираща и идентификационна функция). Първият етап на сродяване между два рода се осъществява при сватосването на момата и ергена. В зависимост от начина, по който протича разговорьт, той се дели на два вида. При първия целта на посещението се разкрива директно, а при втория - с помощта на иносказателни форми. От отговора, който получават сватовниците зависи и развитието на целия обред. Отказът обикновено се прави чрез утвърдени фразеологизми, носещи информацията, че момата не е готова за женитба, с което се цели да не се засегне другата страна: „Хубаво, ама не сме втасали, (...) още е малка, не е научена още къща да върти, не е уготвена още с дарове и сиапь (прикя)" (СбНУ Х: 49-50; СбНУ IX: 34). Тези изрази са добили характер на готови формули, посредством които се улеснява комуникативната функция на словото. В тях са заложени изискванията, на които трябва да отговаря момата, за да получи правото да встьпи в брак, с което тази съставна част на обредния диалог изпълнява нормативна функция. Когато всички тези норми са изпълнени отговорът е положителен и диалогът продължава с уговаряне на деня на годежа, както и на други подробности, свързани със сватбения обреден комплекс. В случаите на иносказателното говорене се цели предпазване на момата и ергена от уроки, а обредното слово извършва превантивна магия. По време на самата сватба се осьществява диалог, наречен обредното обещаване на дарове. Той придружен от засичане с резки по касата на вратата и има за цел да осигури домакинството и стопанството на младото семейство, с което се гарантира успешния завършек на процеса на социализация. Друг характерен за сватбата обреден диалог е задаването на гатанки. Отгатването им показва зрелостта на младоженците и готовността им за семеен живот, с което се гарантира успешността на брака и приобщаването на младоженците. 


\section{3. Функции на обредното мълчание}

Отсъствието на вербална страна в обреда не винаги е равносилно на липсата на съобщение. Известно е, че поради полисемантичната си структура обредното слово е съставна част от кодираната система на обреда. По подобен начин разглеждаме и отсъствието на вербална изява, тъй като мълчанието има силна обредна натовареност и многопластовост на значението.

В традиционната култура на българина мълчанието се възприема като белег за сакралност. То маркира преминаването от културно към природно пространство. Ролята му на табу по отношение на говоренето има както превантивна, така и нормативна функция, тъй като задава нормите на поведение при среща с отвъдното. Ритуалното мълчание е обусловено от няколко обстоятелства - свързано е с промените в природата и/или в социалната структура, които маркират протичането на преход. В този период обредните лица са длъжни да спазват норми на поведение с обратен на културното пространство знак и затова мълчанието в обреда се явява норма на поведение, чието спазването гарантира успешен изход от протичащата промяна, т.е. мълчанието изпълнява функцията на средство за осигуряване на успешното завършване на прехода.

Обредните действия се извършват на раницата между културното и природното пространство - пространство, достьпно за присъствието на сили и представители на отвъдното, застрашаващи като обредното лице, така и социума. Като предпазен механизъм в тези случаи се използва именно мълчанието, тъй като чрез него обредното лице се идентифицира с отвъдното и неговите представители, а това го се преврьща в медиатор, способен да осигури желаното плодородие (и да космизира времето и пространството).

В сватбената обредност мълчанието (говеенето) е не само признак за маргиналност (чуждост), но и знак за покорство и почитание на невестата към свекровото семейство. В този случай говеенето се явява норма не само на обредно поведение, но и на социално.

Забраните и ограниченията създават необходимите условия за осъществяване на обреда, който ще позволи да бъде преодоляна успешно кризата в социалната система. Те очертават митологичното 
пространство, в което се намира човекът - носител на традицията и задават нормите за допустимо и недопустимо в процеса на преход. И в този смисъл мълчанието (като забрана за говорене) има нормативна функция, тъй като определя типа поведение по време на обреда.

В заключение можем да обобщим, че словото е едновременно сила и заклинателен процес, способен да оказва въздействие в различни посоки. Негова специфика е, че във фолклорния обред то съществува с помощта на различни формални и съдържателни средства. Затворено в определена от „законите” на обреда рамка то варира и подлежи на интерпретации в сравнително малка степен. За сметка на това са създадени множество видове слово, които имат свое място и функции в съответния ритуал. Посредством обредното слово се осъществява непосредствено обредно общуване на всички нива от отделните участници в обреда, осигурява се успешното извършване на преход от един социален статус към друг, както и желаното изобилие и плодородие, предпазва се индивида и социума от „злите сили и вредни влияния". Магическото въздействие на словото в обреда е предпоставено от вярата в неговата сила и значение, а знаковият му характер и използването на определени формули го превръща в специфичен код в ритуала и норма на поведение.

\section{Списък на съкращения}

АЕИМ: Архив на Етнографски институт с музей.

АИФ: Архив на Института за фолклор.

СбНУ: Сборник за народни умотворения и народопис. 
